\title{
Spheno-Orbital Meningioma with Cavernous Sinus Extension
}

\author{
Rodolfo Figueiredo de Carvalho ${ }^{1}$ Artur Nóbrega Lima de Morais ${ }^{1} \quad$ Leonardo Desessards Olijnyk $^{1}$ \\ Adriana Azeredo Coutinho Abrao ${ }^{1}$ Claudia Zanatta ${ }^{1}$ Carlos Eduardo da Silva ${ }^{1,2}$
}

${ }^{1}$ Department of Neurosurgery and Skull Base Surgery, Hospital Ernesto Dornelles, Porto Alegre/RS, Brazil

2 Department of Anatomy, DCBS, Federal University of Health

Sciences of Porto Alegre- UFCSPA, Porto Alegre/RS, Brazil

J Neurol Surg B Skull Base 2022;83(suppl S3):e611-e612.
Address for correspondence Carlos Eduardo da Silva, MD, PhD, Porto Alegre, Rio Grande do Sul, Brazil (e-mail: dasilvacebr@yahoo.com.br).

\begin{abstract}
We present a case of a 37-year-old female, with progressive left eye proptosis and an extensive ipsilateral en plaque spheno-orbital meningioma, with diffuse involvement of the lateral wall of the cavernous sinus and the orbit.

A cranio-orbital zygomatic approach was performed to reach all extension of the lesion. We made an extradural clinoidectomy and an extensive bone removal of the orbit, exposition of the superior and lateral walls of the cavernous sinus, unroofing of the optic canal, superior orbital fissure, foramen rotundum, and foramen ovale. We performed the peeling of the lateral wall of cavernous sinus with total removal and preservation of the cranial nerves anatomy and function.

In this video, we illustrate the importance of the first time aggressive removal of such tumors. We also demonstrate the concept that secondary invasion of the cavernous sinus are suitable for removal with cranial nerve preservation.

The link to the video can be found at https://youtu.be/GJmkqVa6jSs.
\end{abstract}

Conflict of Interest

None declared.

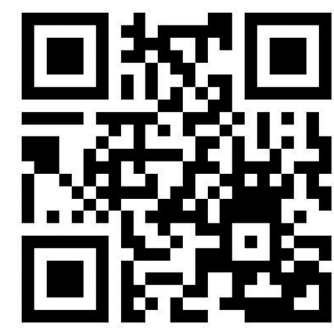

received

March 22, 2020

accepted

October 31, 2020

published online

April 8, 2021

www.thieme.com/skullbasevideos

www.thieme.com/jnlsbvideos
DOI https://doi.org/ 10.1055/s-0041-1725942. ISSN 2193-6331.

\footnotetext{
(C) 2021. The Author(s).

This is an open access article published by Thieme under the terms of the Creative Commons Attribution-NonDerivative-NonCommercial-License, permitting copying and reproduction so long as the original work is given appropriate credit. Contents may not be used for commercial purposes, or adapted, remixed, transformed or built upon. (https://creativecommons.org/ licenses/by-nc-nd/4.0/) Georg Thieme Verlag KG, Rüdigerstraße 14, 70469 Stuttgart, Germany
} 


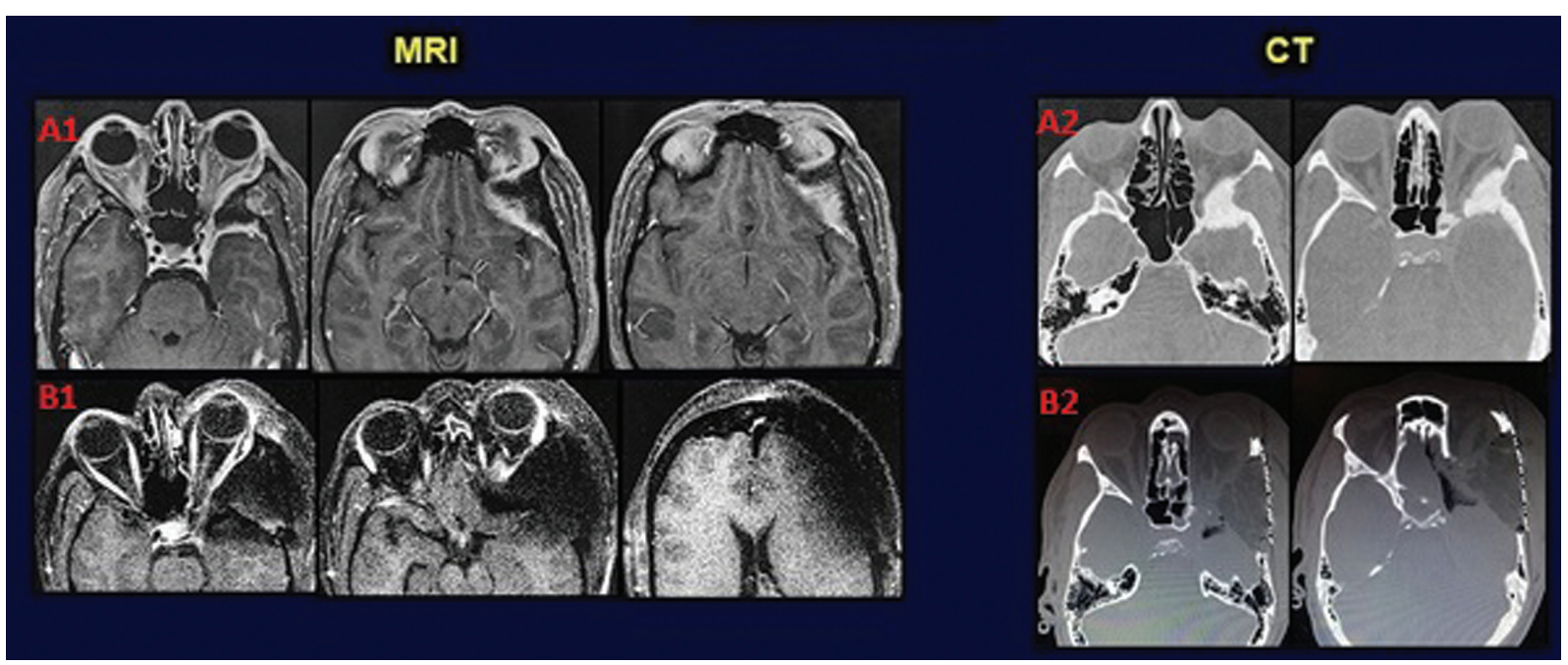

Fig. 1 (A) Preoperative imaging: (A.1) axial MRI demonstrating the diffuse involvement of the frontal, temporal, sphenoid dura, and the lateral wall of the cavernous sinus (A.2) axial CT show the bone involvement. (B) Postoperative imaging: (B.1) axial MRI demonstrating complete resection of the tumor (B.2) axial CT show bone removal and reconstruction of the skull base. CT, computed tomography; MRI, magnetic resonance imaging.

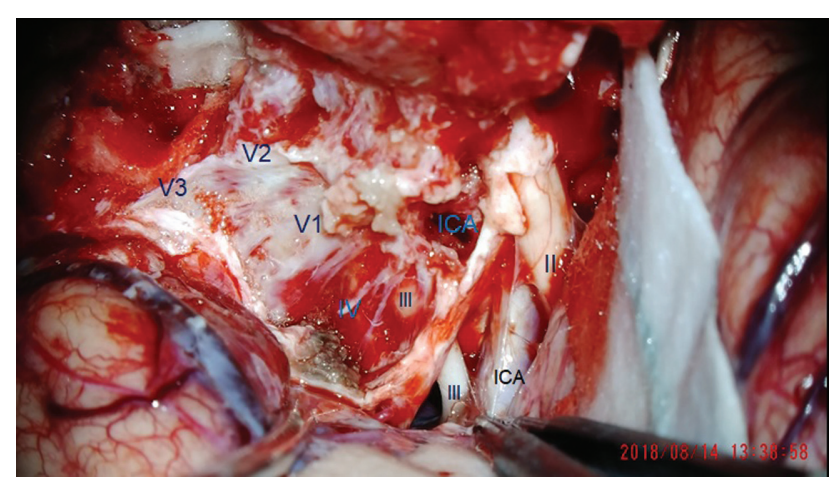

Fig. 2 Peeling of the middle fossa: (II) optic nerve, (ICA in black) ICA in subarachnoid space, (ICA in blue) ICA in the Clinoidal Triangle, (III) oculomotor nerve, (IV) trochlear nerve, (V1) ophthalmic nerve, (V2) maxillary nerve, (V3) mandibular nerve. ICA, internal carotid artery. 